American Journal of Pharmaceutical Education 2020; 84 (8) Article 7875.

\title{
RESEARCH
}

\section{Effectiveness of Issuing Well-being Challenges to Nudge Pharmacy Students to Adopt Well-being Protective Behaviors}

\author{
Jeff Cain, EdD, MS \\ University of Kentucky College of Pharmacy, Lexington, Kentucky \\ Submitted October 7, 2019; accepted February 5, 2020; published August 2020.
}

Objective. To assess the effectiveness of well-being challenges embedded within a pharmacy management course to influence student adoption of positive well-being behaviors.

Methods. Four optional, month-long well-being challenges addressing smartphone use, gratitude, sleep, and exercise were designed and administered within a pharmacy management course. Participants completed a reflective survey documenting reasons for participation, prior behaviors, and intentions to continue the behaviors.

Results. Ninety-three percent $(n=126)$ of students enrolled in the course participated in at least one well-being challenge, and $82 \%(n=104)$ of participants completed two or more challenges. The majority of participants (ranging from $88 \%$ to $100 \%$ per challenge) indicated they intended to attempt or definitely continue the behaviors after the challenge(s) was completed.

Conclusion. A strategy of well-being challenges can be an effective way to influence students to adopt well-being protective behaviors.

Keywords: well-being, nudging, behavioral economics

\section{INTRODUCTION}

Student well-being has become an important issue within pharmacy education. In 2017 and 2018, the American Association of Colleges of Pharmacy (AACP) adopted two policy statements on well-being: "AACP believes that all administrators, faculty, staff, preceptors, student pharmacists and alumni should contribute to a culture of wellness and resilience in pharmacy education" and "AACP encourages schools and colleges of pharmacy to proactively promote overall wellness and stress management techniques to students, faculty, and staff." Addressing the nuanced and complex issues of overall student well-being will require multiple approaches at a variety of institutional and personal levels. Pharmacy schools and faculty members have attempted to help students improve aspects of their well-being through a range of interventions including yoga, meditation, and mindfulness. ${ }^{2-4}$ Research has shown that these types of activities, as well as the adoption of various protective factors such as adequate sleep, expression of gratitude, social relationships, and exercise can all contribute to overall well-being. ${ }^{5-7}$ While this is somewhat common knowledge and many students adopt these behaviors as a

Corresponding Author: Jeff Cain, University of Kentucky, College of Pharmacy, 114M Lee T. Todd, Jr. Building 789

South Limestone Dr, Lexington, KY 40536-0596. Tel: 859257-4429. Email: jeff.cain@uky.edu stress coping mechanism, there are still significant numbers of students who do not. ${ }^{8-11}$ Several studies have shown that college students have difficulty in establishing and maintaining health-promoting behaviors. ${ }^{12}$ Although many colleges and schools may offer formal and informal information sessions encouraging students to take proactive measures toward improving their health and wellbeing, research literature regarding the effectiveness of these sessions in influencing students' well-being behaviors is sparse.

One potential way to help students adopt well-being protective behaviors is to borrow strategies and approaches from the field of behavioral science. ${ }^{13}$ Many governing agencies and health care policy groups have begun to use "nudging" principles to influence adoption of healthy lifestyle habits. ${ }^{14}$ Nudging is predicated on research showing that people do not always behave rationally and are subconsciously influenced by biases and context. ${ }^{15}$ Examples of these influences include biases toward status quo, aversion to loss, attention effects, and incentives. ${ }^{16}$ Nudging strategies use insights from these same psychological influences to subconsciously encourage ideal behaviors in a noncoercive way that does not impose negative consequences. ${ }^{16}$ In other words, as the name implies, nudging strategies use psychological principles to "nudge" people toward freely choosing preferred behaviors while not penalizing those who choose differently. 


\section{American Journal of Pharmaceutical Education 2020; 84 (8) Article 7875.}

Anecdotal conversations with students reveal that many have a desire to make better choices regarding their well-being but fail to do so. School, work, and social demands are just a few of the factors that may distract students from attending to behaviors that optimize health. If a hectic student lifestyle with heavy cognitive demands contributes to students' lack of attention toward positive well-being behaviors, then salience and inertia are two specific behavioral economics principles that may be applicable. The principle of salience dictates that people are more likely to act on items to which their attention is directed. ${ }^{17}$ A second behavioral economics principle to consider when influencing busy pharmacy students to adopt new behaviors is inertia. The human tendency toward maintaining the status quo is sometimes a difficult barrier to behavior change. ${ }^{18}$ Thus, a catalyst may be required to help students clear that first mental hurdle and initiate change.

The project described in this paper was designed to nudge pharmacy students toward adopting and/or increasing behaviors conducive to their overall well-being. This study reports on the effectiveness of a strategy informed by the nudging principles of inertia and salience, consisting of a series of well-being challenges embedded in a pharmacy management course to encourage students to adopt well-being protective behaviors. A secondary objective of the study was to determine if the challenges improved student perceptions of their ability to increase their personal well-being.

\section{METHODS}

The strategy was implemented in a required threecredit-hour pharmacy management course offered to students in the third professional (P3) year of pharmacy school at the University of Kentucky College of Pharmacy. Four monthly well-being challenges (Table 1), spanning from January through April 2019, were designed by the instructor to address four different factors that have been shown to contribute to well-being. The four challenges, which involved smartphone use, feelings of gratitude, sleep behaviors, and exercise, were selected based on research showing their significance to well-being and to provide a diverse set of experiences. The design of the overall strategy was informed by the behavioral economics principles of salience and inertia. ${ }^{18}$ How these principles factored into the design is described below.

The most important design aspect was making the four protective behaviors salient or, in other words, bringing them to the forefront of students' attention. Salience was achieved by elevating the behaviors to a component of the course through the assignment feature within Canvas Learning Management System (Instructure, Inc, Salt Lake City, UT) and automated Canvas announcements regarding each challenge. Second, the "challenge" aspect and the incentives (one extra credit point for completing each challenge) were included to influence students to overcome inertia (the state of not moving or changing) and activate the desired behavior. ${ }^{19}$ Within the context of the course, the extra credit point(s) were trivial, amounting to only . $2 \%$ of the final grade per challenge. This incentive was intentionally slight in order to follow a fundamental nudging design philosophy of not significantly disadvantaging anyone who chose not to participate. ${ }^{16}$

Table 1. Requirements for Each Challenge Included in a Study Intended to Nudge Students to Adopt Well-being Protective Behaviors

\begin{tabular}{|c|c|c|}
\hline Challenge Name & Month & Requirements \\
\hline Smartphone Challenge & Jan & $\begin{array}{l}\text { Change the default color setting to grayscale } \\
\text { mode } \\
\text { Do not sleep with or near your smartphone } \\
\text { Turn off sound/vibration notifications for social } \\
\text { media } \\
\text { Move all social media icons off your home } \\
\text { screen }\end{array}$ \\
\hline Gratitude Challenge & Feb & $\begin{array}{l}\text { Each day, document } 20 \text { different things for } \\
\text { which you are grateful }\end{array}$ \\
\hline Sleep Challenge & Mar & $\begin{array}{l}\text { Sleep a minimum of } 6 \text { hours each night } \\
\text { Average a minimum of } 7 \text { hours of sleep per } \\
\text { night each week }\end{array}$ \\
\hline Exercise Challenge & Apr & $\begin{array}{l}\text { Participate in } 30 \text { minutes of physical activity of } \\
\text { your choice (walking, running, weightlifting, } \\
\text { dancing, yoga, mobility exercises, etc.) } \\
\text { Exercise a minimum of } 4 \text { days per week } \\
\text { Exercise a minimum of } 3 \text { hours per week }\end{array}$ \\
\hline
\end{tabular}




\section{American Journal of Pharmaceutical Education 2020; 84 (8) Article 7875.}

On the first day of class, following a brief lecture on the trend of organizations providing well-being initiatives to employees in the workplace, students were informed of the well-being challenges. The potential benefits of behaviors from each of the challenges for reducing stress, anxiety, and depression were extolled. Students were informed that participation in the challenges was optional and, aside from the potential positive effects on participant well-being, the only other incentive was one extra credit point for completing the challenge and respective reflective survey.

At the end of each well-being challenge, participants were given one week to complete a five-question online reflective survey delivered anonymously via Canvas. The survey was designed to record participation in the challenge, as well as reasons for participating, prior behaviors, and future intentions of continuing the behaviors. Two students pilot tested the survey for face validity, with only minor text modifications made to the final version. Survey results were downloaded in Microsoft Excel and analyzed for descriptive statistics.

Effectiveness of this strategy to nudge students toward improved well-being behaviors was determined by students' short-term adoption of the behaviors during the semester and long-term intentions to continue the behaviors. Short-term success was defined as $50 \%$ of the class $(n=68)$ participating in two or more challenges. Long-term success was defined as $50 \%$ of participants of each challenge indicating intentions to continue the "shift" in behaviors from their baseline after the challenge ended. Because large differences in the numbers of students who exhibited the behaviors of each challenge prior to the course, the long-term success of the strategy was ultimately measured differently for the smartphone and gratitude challenges than the challenges for sleep and exercise. Effectiveness of the smartphone and gratitude challenges was measured by the degree to which students who had never exhibited the specific behaviors prior to the challenge intended to continue the specified behaviors after the challenge. For sleep and exercise, there were very few participants who had never met the requirements prior to the challenge. Therefore, success was measured by examining whether those who did not always exhibit the behaviors prior to the challenge definitely intended to continue the behaviors afterwards. This study received exempt approval from the University of Kentucky Institutional Review Board.

\section{RESULTS}

The majority of students enrolled in the course $(93 \%$, $\mathrm{n}=126$ ) participated in at least one well-being challenge and consented to have their results included in the study for analysis. Of the 126 students who participated in the challenges, 22 (17\%) completed one challenge, $35(28 \%)$ completed two challenges, 41 (33\%) completed three challenges, and 28 (22\%) completed all four challenges. The sleep challenge was the most attempted, with $87 \%$ $(\mathrm{n}=118)$ of students completing it. The least attempted challenge was exercise, with only $37 \%(n=50)$ of students completing it.

The primary reason indicated for participation in each challenge (ranging from 86\%-95\%) was the opportunity to earn extra credit. Additional reasons, such as increasing personal wellbeing or productivity, varied widely according to the specific challenge. Prior to the course, the majority of participants $(64 \%$ and $85 \%$, respectively) never or rarely met the criteria of the smartphone and gratitude challenges, while only $10 \%$ and $26 \%$, respectively, never or rarely met the criteria for the sleep and exercise challenges.

Regarding the long-term success of the challenges, the majority of participants (ranging from $88 \%$ to $100 \%$ ) indicated that they intended to attempt to continue or definitely continue the behaviors after the challenge was completed. For the smartphone challenge, $88 \%$ of the 40 participants who had never exhibited the behaviors prior to the challenge intended to either attempt to continue $(n=28)$ or definitely continue $(n=7)$ the behaviors after the challenge was complete. For the gratitude challenge, $83 \%$ of the 47 participants who had never exhibited the behaviors prior to the challenge intended to either attempt to continue $(n=32)$ or definitely continue $(n=7)$ the behaviors after the challenge was complete. Fortyeight percent $(n=38)$ of the 80 participants in the sleep challenge who did not always exhibit the behaviors prior to the challenge indicated they would definitely continue them. Fifty-four percent $(n=18)$ of the 33 participants in the exercise challenge who did not always exhibit the behaviors prior to the challenge indicated they would definitely continue them post-challenge.

Participants who indicated that they perceived themselves more able to enhance their personal well-being after the challenge ranged from $46 \%$ in the sleep challenge to $66 \%$ in the gratitude challenge. A detailed breakdown of participation and survey responses for each challenge are presented in Table 2.

\section{DISCUSSION}

This study examined a strategy to promote positive well-being behaviors among students by incorporating optional well-being challenge assignments into a required pharmacy management course. The results of this study add to the literature regarding strategies to influence student well-being behaviors and provide insight into the 


\section{American Journal of Pharmaceutical Education 2020; 84 (8) Article 7875.}

Table 2. Pharmacy Students' Reasons for Participating in Well-being Challenges, Behaviors Prior to Challenges, and Intentions and Perceptions After Challenges $(\mathrm{N}=136)^{\mathrm{a}}$

\begin{tabular}{|c|c|c|c|c|}
\hline Challenges & $\begin{array}{l}\text { Smartphone, } \\
\text { No. }(\%)\end{array}$ & $\begin{array}{l}\text { Gratitude, } \\
\text { No. }(\%)\end{array}$ & $\begin{array}{l}\text { Sleep, } \\
\text { No. }(\%)\end{array}$ & $\begin{array}{l}\text { Exercise, } \\
\text { No. }(\%)\end{array}$ \\
\hline Participants in challenge $^{\mathrm{a}}$ & $95(70)$ & $64(47)$ & $118(87)$ & $50(37)$ \\
\hline \multicolumn{5}{|l|}{$\begin{array}{l}\text { Reasons for participating in the challenge } \\
\text { (all that apply) }\end{array}$} \\
\hline Points & $86(90)$ & $61(95)$ & $107(91)$ & $43(86)$ \\
\hline Increase personal productivity & $48(50)$ & $6(9)$ & $51(43)$ & $24(48)$ \\
\hline Needed for personal well-being & $85(89)$ & $27(42)$ & $47(40)$ & $35(70)$ \\
\hline Curious of effect & $27(28)$ & $20(31)$ & $79(67)$ & $11(22)$ \\
\hline Other & $0(0)$ & $5(8)$ & $1(1)$ & $0(0)$ \\
\hline \multicolumn{5}{|l|}{ Met criteria prior to challenge ${ }^{b}$} \\
\hline Never & $40(42)$ & $47(73)$ & $2(2)$ & $2(4)$ \\
\hline Rarely & $21(22)$ & $8(12)$ & $9(8)$ & $11(22)$ \\
\hline Often & $33(35)$ & $9(14)$ & $69(58)$ & $20(40)$ \\
\hline Always & $1(1)$ & $0(0)$ & $38(32)$ & $17(34)$ \\
\hline \multicolumn{5}{|l|}{ Intentions to continue $^{\mathrm{b}}$} \\
\hline No intentions to continue behavior & $8(8)$ & $8(12)$ & $1(1)$ & $0(0)$ \\
\hline Attempt to continue behaviors & $80(84)$ & $49(77)$ & $44(37)$ & $16(32)$ \\
\hline Definitely continue behaviors & $7(7)$ & $7(11)$ & $73(62)$ & $34(68)$ \\
\hline \multicolumn{5}{|l|}{ Ability to improve personal well-being ${ }^{\mathrm{b}}$} \\
\hline Less able than before challenge & $3(3)$ & $1(2)$ & $1(1)$ & $0(0)$ \\
\hline Equally able as before challenge & $35(37)$ & $21(33)$ & $63(53)$ & $23(46)$ \\
\hline More able than before challenge & $57(60)$ & $42(66)$ & $54(46)$ & $27(54)$ \\
\hline
\end{tabular}

application of behavioral economics principles within a formal educational setting.

The fundamental question to be answered by this study was could an unobtrusive and low-cost (in terms of instructor time and resources) optional course assignment influence students to adopt behaviors linked with wellbeing. The goal of these assignments was to nudge students' well-being behaviors in four areas (smartphone use, gratitude, sleep, and exercise) along the continuum from never exhibiting these behaviors to always exhibiting these behaviors. Given the minimal amount of instructor time and effort involved with each strategy, influencing even a small percentage of students to adopt and/or continue one or more of the behaviors could be considered a success. Overall, those shifts were positive, but varied with each challenge and each student according to the point at which their behavior(s) resided on the continuum prior to each challenge. With regard to short-term success, $76 \%$ of the class completed two or more of the four challenges, which was more than the predetermined goal of 50\%. More importantly, students' intentions to continue the behaviors long term indicated a positive shift in behaviors from baseline, across all challenges. The gratitude challenge was the least successful regarding long-term intentions, but was just two students short of meeting the criteria for success.
This is one of the first studies to examine a strategy implemented within a formal education curriculum to influence students' adoption of positive well-being behaviors. The success of this strategy compares favorably with results from the only other study of this sort discovered through a literature review. An intervention with medical students conducted by Ball and colleagues included a lecture, written information about self-care habits, and a group discussion. Their intervention targeted exercise, sleep, alcohol use, and socialization and was moderately successful, with some improved sleep and exercise habits among participants in the intervention group. However, there were no significant changes in alcohol use or socialization among students in the control group. ${ }^{20}$ In contrast, this study design, which used well-being challenges, considered the inertia factor and required actual student participation in order for the challenge to serve as a catalyst. The well-being challenges also required minimal time and resources on behalf of the instructor and college. Once the assignments were designed and programmed in Canvas, no additional time, effort, or classroom resources were needed by the instructor. One of the most appealing features of this strategy is that it could be easily transferred to other institutions. Results from this study can 


\section{American Journal of Pharmaceutical Education 2020; 84 (8) Article 7875.}

also be used to inform the design of other behavioralchange studies.

Although this study did not directly test a nudging strategy, philosophically it was designed to nudge students toward desired behaviors. The results are similar to those from other strategies designed to nudge student behaviors in other aspects of education. Pugatch and Wilson report that sending a one-time postcard reminder to students about the availability of tutoring services, which used the nudging principle of salience, increased utilization of tutoring services by $23 \%$ of the control group mean. ${ }^{21}$ Similarly, Soricone and Endel reported that in a randomized control trial of more than 2700 students, a nudging intervention that consisted of sending positive reinforcement text messages to students resulted in a significant $10 \%$ increase in persistence/retention for STEM students compared to the control group. ${ }^{22}$ Results of all these studies offer insight into the possibility of using nudging strategies to influence desired student behaviors.

There were several interesting observations regarding student participation in the challenges. The smartphone challenge presented some of the most intriguing results with $89 \%$ of participants reporting they undertook the challenge because it was necessary for their own personal well-being. This is an indication that students are at least somewhat aware of the issues of smartphone overuse, and they desire to limit use. That recognition is similar to results from Aust and colleagues' study in which students reported the need to control their screen time. ${ }^{23}$ There were also several anecdotal comments from students stating that time spent mindlessly browsing their phone was greatly reduced and that they had shared this challenge with other family members and friends. While those conversations indicated the desired effect of the challenge, several students also commented that it was one they initially did not like. Specifically, the requirement to turn display settings to grayscale meant that viewing photos on Instagram and Facebook were significantly less appealing and reduced their desire to even look at them, which was why that requirement was part of the challenge.

Reasons that students provided for participating in the challenges offer some interesting areas for discussion. As expected, and discussed in further detail below, the opportunity to earn an extra credit was a major contributing factor to participation. Second, a large percentage (40\% to $89 \%$ ) of students indicated that they took part in the challenges because they realized they needed to for their own personal well-being. These results suggest that many students are at least informed and knowledgeable about personal care to ensure well-being. Whether the other students were unaware of the positive effects on well-being that the challenges might have or whether that was simply not a reason for them to participate is unknown. Finally, based on reasons provided, nearly half of participants realized that adequate sleep and exercise and less time spent on smartphones can be important to personal productivity. It is also not known whether the remaining participants recognized the potential productivity benefits or not.

Two of the more surprising results of the study were the high percentage of students already meeting the requirements of the sleep challenge and the low number of students undertaking the exercise challenge. Ninety percent of participants indicated that they often or always met the sleep requirements. This counters previous research results by Cates and colleagues ${ }^{24}$ and Zeek and colleagues $^{25}$ in which the majority of pharmacy students reported suboptimal sleeping habits. One possible explanation for the better sleep habits of participants in this study is that the course load and scheduling during that semester may have been more conducive to better sleep habits. Another possible explanation is that this study focused only on quantity of hours slept, whereas other studies incorporated other aspects of sleep quality. The second surprising observation from this study was that only $37 \%$ of students participated in the exercise challenge, especially given previous research by Garber ${ }^{8}$ indicating that $75 \%$ of study participants used exercise as a stress coping mechanism. Finally, because this challenge was near the end of the semester, students had a good indication of their final course grade and many may have felt an extra credit point was unnecessary and therefore simply did not complete the reflective activity on exercise.

While this study did not directly test aspects of the nudging design through controlled experimentation, some insights can be gleaned from the results. First, as expected, the extra credit incentive was influential in overcoming inertia. Even though the incentive was small, it did appear to significantly influence participation, with $86 \%$ to $95 \%$ of participants indicating it was one of their reasons for participating. A majority of students who adopted the behaviors for the first time during the study intended on continuing them. This illustrates the importance of addressing the status quo bias and offers evidence that somehow influencing students to attempt a behavior could potentially lead to that lifestyle change.

There are two notable limitations to this study. First, the study was based on self-report; therefore, the degree to which students actually met challenge requirements could be less than reported. Second, long-term success of the challenge was determined by students' self-report of intentions of continuing the behavior versus actual continuation of a behavior. Future iterations of the well-being 


\section{American Journal of Pharmaceutical Education 2020; 84 (8) Article 7875.}

challenge will involve several changes to the research design, such as focusing on different protective behaviors (eg, hobbies or social support), providing additional prompts throughout the challenges to further increase salience, and eliminating extra credit to determine the extent to which earning points influenced student participation.

\section{CONCLUSION}

This was one of the first studies to examine a courseembedded strategy of promoting student adoption of positive well-being behaviors. The strategy described in this paper used a series of novel well-being challenges embedded in a pharmacy management course to nudge students to adopt or improve behaviors shown to positively influence mental wellness. The extent to which students exhibited the targeted behaviors before the challenge varied, as did participation rates and reasons for participating. A large percentage of participants in this study adopted and/or increased the frequency of wellbeing behaviors, as well as expressed intentions to continue the behaviors long term. Results of the study indicate the potential that this type of strategy may have in influencing other student behaviors. The intervention itself required minimal instructor effort, time, and resources, which makes it easy to replicate in other courses and/or institutions.

\section{ACKNOWLEDGMENTS}

The author thanks Dr. Penni Black for feedback regarding data presentation in this manuscript.

\section{REFERENCES}

1. American Association of Colleges of Pharmacy. AACP Statement on Commitment to Clinician Well-being and Resilience. https:// www.aacp.org/article/commitment-clinician-well-being-andresilience. Accessed July 28, 2020.

2. Lemay V, Hoolahan J, Buchanan A. Impact of a yoga and meditation intervention on students' stress and anxiety levels. Am J Pharm Educ. 2019;83(5):Article 7001.

3. Zollars I, Poirier TI, Pailden J. Effects of mindfulness meditation on mindfulness, mental well-being, and perceived stress. Curr Pharm Teach Learn. 2019; 11(10):1022-1028.

4. O'Driscoll M, Sahm LJ, Byrne H, Lambert S, Byrne S. Impact of a mindfulness-based intervention on undergraduate pharmacy students' stress and distress: quantitative results of a mixed-methods study. Curr Pharm Teach Learn. 2019;11(9):876-887.

5. Skead N, Rogers SL. Stress, anxiety and depression in law students: how student behaviors affect student wellbeing. Monash $U L$ Rev. 2014;40(2):565-588.
6. Wolf MR, Rosenstock JB. Inadequate sleep and exercise associated with burnout and depression among medical students. Acad Psychiatry. 2017;41(2):174-179.

7. Layous K, Chancellor J, Lyubomirsky S. Positive activities as protective factors against mental health conditions. J Abnorm Psychol. 2014;123(1):3-12.

8. Garber MC. Exercise as a stress coping mechanism in a pharmacy student population. Am J Pharm Educ. 2017;81(3):Article 50.

9. Marshall LL, Allison A, Nykamp D, Lanke S. Perceived stress and quality of life among doctor of pharmacy students. Am J Pharm Educ. 2008;72(6):Article 137.

10. Sam AT, Muttusamy B, Yee SM, Ayapanaido T, Parasuraman S. Investigation of stressors affecting a sample of pharmacy students and the coping strategies employed using modified academic stressors scale and brief cope scale: A prospective study. J Young Pharm. 2016;8(2):122-127.

11. Kulig CE, Persky AM. Transition and student well-being: why we need to start the conversation. Am J Pharm Educ. 2017;81(6):Article 100 .

12. Moses J, Bradley GL, O'Callaghan FV. When college students look after themselves: self-care practices and well-being. J Stud Aff Res Pract. 2016;53(3):346-359.

13. Kelly MP, Barker M. Why is changing health-related behaviour so difficult? Public Health. 2016;136:109-116.

14. Quigley M. Nudging for health: on public policy and designing choice architecture. Med Law Rev. 2013;21(4):588-621.

15. Vlaev I, King D, Dolan P, Darzi A. The theory and practice of "nudging": changing health behaviors. Public Adm Rev.

2016;76(4):550-561.

16. Thaler RH, Sunstein CR. Nudge: Improving Decisions About

Health, Wealth, and Happiness. London: Penguin; 2009.

17. Noggle R. Manipulation, salience, and nudges. Bioethics. 2018;32(3):164-170.

18. Samson A, ed The Behavioral Economics Guide 2019. London: Behavioral Science Solutions Ltd; 2019.

19. Ly K, Mazar N, Zhao M, Soman D. A practitioner's guide to nudging. University of Toronto. Research Report Series: Behavioral Economics in Action Web site. https://www.rotman.utoronto.ca/-/ media/Images/Programs-and-Areas/behavioural-economics/ GuidetoNudging-Rotman-Mar2013.pdf. Published 2013. Accessed July 28, 2020.

20. Ball S, Bax A. Self-care in medical education: effectiveness of health-habits interventions for first-year medical students. Acad Med. 2002;77(9):911-917.

21. Pugatch T, Wilson N. Nudging study habits: a field experiment on peer tutoring in higher education. Econ Educ Rev. 2018;62:151-161. 22. Soricone L, Endel B. Nudging to STEM Success: Implementation Report. Boston, MA. 2019.

23. Aust LA, Bockman SA, Hermansen-Kobulnicky CJ. One click away: pilot study of the perceived academic impact of screen time among pharmacy students. Curr Pharm Teach Learn. 2019;11(6):565-570. 24. Cates ME, Clark A, Woolley TW, Saunders A. Sleep quality among pharmacy students. Am J Pharm Educ. 2015;79(1):Article 9. 25. Zeek ML, Savoie MJ, Song M, et al. Sleep duration and academic performance among student pharmacists. Am J Pharm Educ. 2015;79(5):Article 63. 